\title{
Epifania do acontecer poético: aspectos da experiência estética na relação sujeito-obra em terapia ocupacional*
}

\section{Epiphany of the poetic occurrence: aspects of the aesthetic experience between subject-work of art relation in occupational therapy}

\author{
Renata Caruso Mecca ${ }^{1}$, Eliane Dias de Castro
}

\begin{abstract}
MECCA, R. C.; CASTRO, E. D. de. Epifania do acontecer poético: aspectos da experiência estética na relação sujeito-obra em terapia ocupacional. Rev. Ter. Ocup. Univ. São Paulo, v. 20, n. 3, p. 180-187, set./dez. 2009.
\end{abstract}

\begin{abstract}
RESUMO: Aborda-se a experiência estética como fenômeno inerente à relação sujeito-obra no contexto da prática em terapia ocupacional em saúde mental. Trata-se de situações da experiência prática que dizem respeito à possibilidade do sujeito encontrar aspectos de seu estilo de ser numa relação.eu-outro com o produto de sua criação artística. Objetiva-se compreender qual a contribuição que a experiência estética traz para o acontecer poético do sujeito, a emergência de seu gesto criativo e para o início da construção de seu modo de formar. Processo que, na própria matéria sensível em formação, auxilia na recomposição de fragmentos da história pessoal, constrói sentido e forma para a existência, para as vivências cotidianas e possibilita o reconhecimento pelo entorno de um modo singular de acontecer no mundo. $\mathrm{O}$ artigo é parte dos resultados de nossa dissertação de mestrado que consta de uma pesquisa de campo no acompanhamento do processo de realização de atividades artísticas por um grupo de usuários de um serviço de saúde mental, com posterior análise qualitativa dos dados. A contribuição ativa dos participantes do referido grupo na coleta e análise de dados compõe os procedimentos desenvolvidos segundo a pesquisa-ação integral e sistêmica. Têm-se como resultados que o encontro com a obra possibilita o surgimento de novos modos de ser desenrijecidos e fertilizados por um processo de singularização e uma abertura prospectiva para processos de contínuo inventar de si mesmo.
\end{abstract}

DESCRITORES: Terapia Ocupacional. Saúde mental. Arte.

\footnotetext{
* O trabalho é parte integrante da dissertação de mestrado: MECCA, R. C. Experiência estética na terapia ocupacional em saúde mental: gestos na matéria sensível e alojamento no mundo humano. 2008. 263 f. Dissertação (Mestrado em ciências) - Faculdade de Medicina da Universidade de São Paulo, São Paulo, 2008 e teve aprovação da Comissão de Ética para Análise de Projetos de Pesquisa - CAPPesq, do HC- FMUSP, protocolo de pesquisa 1.015/05. Apresentado no VII Congreso Internacional Salud Mental y Derechos Humanos, Buenos Aires, Argentina, de 10 a 13 de dezembro de 2008.

1 Terapeuta ocupacional, docente do curso de Terapia Ocupacional do Centro Universitário São Camilo.

2 Docente do Curso de Terapia Ocupacional da USP.

Endereço para correspondência: Rua Loureiro Batista, 202, cep: 04019-120, São Paulo -SP. E-mail: meccadasartes@yahoo.com.br
} 
MECCA, R. C.; CASTRO, E. D. de. Epifania do acontecer. Rev. Ter. Ocup. Univ. São Paulo, v. 20, n. 3, p. 180-187, set./dez. 2009.

\section{INTRODUÇÃO}

$\mathrm{E}$ ste artigo é parte dos resultados de nossa pesquisa de mestrado cujo objetivo é discorrer sobre a experiência estética na relação que pessoas com sofrimento psíquico grave estabelecem com o produto de sua criação artística no contexto terapêutico ocupacional em saúde mental. A pesquisa ocupou-se em traçar uma elaboração teórico-prática a partir do acompanhamento de um grupo de atividades artísticas com pessoas que fazem uso de um serviço de saúde mental da rede pública, associada a uma pesquisa bibliográfica dos campos da arte de da saúde mental (MECCA, 2008).

A experiência estética se relaciona a uma dimensão existencial da vida das pessoas e pode ser suscitada no contato com qualquer objeto ou fenômeno. Ela evoca forças vivas que constituem a subjetividade, conecta o sujeito sensorialmente ao entorno, localiza-o entre outros num cenário estético intersubjetivo e, ao mesmo tempo, lança-o num outro espaço-tempo que desmancha formas costumeiras de lidar com as situações cotidianas e inventa novos modos de ser, fertilizados por um processo de singularização.

Entendemos a experiência estética na relação com o produto do fazer artístico como um encontro entre o sujeito e aspectos da sua maneira de ser que passam a acontecer na produção ou em situações compartilhadas com outros. É parte inerente ao processo de criação e se constrói pelas maneiras de fazer do sujeito num contexto de cuidado. As maneiras de fazer são campos de experimentação e de criação da subjetividade que operam uma inscrição do sujeito no mundo, processo que ao nosso ver, é percebido pelo sujeito como uma experiência estética (MECCA, 2008).

Traçou-se um percurso de elaboração teórico-prática, que resultou em duas grandes categorias temáticas. A parte aqui apresentada refere-se a uma das subcategorias de análise desenvolvidas como resultado, que abarca situações que habitam um espaço entre sujeito e obra, constituem estados momentâneos de epifania e possibilitam ao sujeito constituir-se esteticamente. Este processo se dá a partir de uma fusão momentânea do sujeito com o objeto estético e também um distanciamento que pressupõe uma separação eu-outro, e, portanto, provoca sensações de reconhecimento de si nas produções e concomitante reconhecimento do outro (MECCA, 2008).

São situações que remontam estados de não-integração e nas quais é possível o acontecer poético de alguém como potencial de um vir a ser outro. Dizem respeito a experiências que criam espaços de presença para o informe, o inusitado, o invisível. Espaço de respiração em perspectiva, onde "criar é sempre criar um futuro" (PASSERON, 1996, p.27 apud SOUSA, 2002, p.145).

Falaremos da possibilidade de o sujeito reconhecer no produto de sua criação artística características de seu estilo de ser, seu modo de acontecer singular e poder dar-lhe sentido. Denomina-se de estilo de ser, características de si, de sua família e de sua cultura que se organizam desde os primeiros estágios do desenvolvimento. Potencialidades de ser que dizem respeito a maneira de o sujeito se apresentar no mundo e que permitem com que a pessoa, a cada etapa da vida, reencontre a si no outro e no mundo. Modo como a existência do sujeito acontece que é organizado sensorialmente e apreendido pela poesia de sua fala, de sua corporeidade, de seu gesto criador (SAFRA, 1999).

Para Pareyson (1989), a vida do autor está presente na obra, mas esta é uma presença especial, pois ela não se constitui de fatos e atos singulares reconstituíveis numa biografia, ela é antes de tudo a presença de uma personalidade que se formou ao longo da vida e que se encontra na forma de traçar linhas, misturar cores, combinar imagens. Ele dá o nome de estilo a essa presença. É através do estilo e do gesto, que são sensibilidade do artista tornada modo de formar, que a personalidade e o mundo do artista entram na obra.

Para este autor, a arte é operação expressiva e não veículo de expressão de um conteúdo outro. Isso quer dizer que a forma é expressiva, pois seu ser é um dizer, ela não porta um significado além dela, mas é um significado. Não é possível distinguir expressão daquilo que ela exprime, o sentido se dá pela e na forma.

Esse apontamento é fundamental para nosso estudo porque nos auxilia a atenuar a importância dos episódios da vida pregressa, como conteúdo temático das obras a ser decifrado e argumentar em favor da percepção do estilo, da permissão ao acontecer poético de alguém e da oferta de possibilidades para a formação do gesto criativo como um importante procedimento em terapia ocupacional, que possibilita uma formação contínua e prospectiva dos sujeitos atendidos e de suas maneiras de estar no mundo.

\section{MATERIAL E MÉTODOS}

O presente estudo foi realizado a partir de pesquisa bibliográfica que abarcou os campos da arte, da saúde mental e da atenção em terapia ocupacional nesse campo; somados a uma pesquisa de campo no acompanhamento, durante 13 meses, de um grupo de atividades artísticas desenvolvido em um serviço público de saúde mental, destinado a tratar de pessoas cujo sofrimento psíquico se encontra em fase 
aguda e na pós-crise: o Centro de Atenção Psicossocial de Guarulhos, São Paulo.

O grupo acompanhado, denominado Oficina de Bricolagem, ocorria semanalmente e tinha por proposta a produção grupal de painéis, instalações entre outros objetos através de técnicas do fazer artístico, que eram expostos no ambiente da instituição ou ocupavam espaços no território da cidade. Do grupo faziam parte usuários do serviço, que se encontravam em sistema intensivo e semi-intensivo de tratamento ${ }^{1}$.

O método utilizado foi a pesquisa-ação, que consta da análise e reflexão de um projeto de intervenção, proposto no campo de pesquisa pelo próprio pesquisador em construção conjunta e interativa com o grupo, que intervém no processo de coleta, definição de problemas e análise de dados. Pressupõe um processo de emancipação e apropriação da pesquisa pelos sujeitos, pois coloca em foco a geração de soluções para problemas práticos e o desenvolvimento de habilidades e capacidades, fazendo com que se engajem na pesquisa e no desenvolvimento e implementação de atividades (MEYER, 2005).

$\mathrm{O}$ registro dos encontros do grupo era discutido com os atores-participantes a cada início de sessão. Foi realizada a análise qualitativa do material coletado segundo a análise em pesquisa-ação integral e sistêmica (MORIN, 2004) e as conclusões preliminares foram revisadas pelos atoresparticipantes em validação de dados.

A Oficina de Bricolagem foi um grupo realizado semanalmente no CAPS, composto por adultos com sofrimento psíquico grave, que participaram por períodos diversos deste grupo. No período em que se realizou a coleta de dados desta pesquisa, 23 pessoas participaram deste processo. Alguns participantes freqüentaram o grupo mesmo após a alta do serviço, outros não retornaram após a alta. Esta variabilidade na participação e composição grupal foi contornada pelo estabelecimento de um contrato com o pesquisador e com as diferentes etapas do processo de pesquisa. Desta forma, cada grupo realizado era constituído por 10 pessoas, no máximo, por encontro. A coleta foi realizada ao longo de 13 meses e momentos de validação dos dados foram instaurados, discutidos e validados com os participantes do período.

Os episódios aqui narrados apresentam uma das subcategoria de análise denominada 'Epifania ${ }^{2}$ do acontecer poético', e referem-se à construção de um painel de pintura a partir de fotografias produzidas pelos próprios participantes.
Cenas sobre atividades significativas ou locais e situações nas quais os participantes sentiam-se pertencentes foram montadas e fotografadas. Posteriormente foram transformadas por colagem e projetadas numa tela para serem pintadas e transfiguradas pela atividade plástica.

\section{DISCUSSÃO DOS RESULTADOS}

A sub-categoria apresentada a seguir é fruto de um processo de análise que partiu da leitura flutuante do material coletado associado à teoria e, posteriormente, associado às categorias validadas pelos participantes. Para esta discussão dos resultados, apresentamos cenas narradas a partir do acompanhamento de D, G, M, e MA, momentos destacados do conjunto de atendimentos e que foram discutidos na validação.

Desta forma, quando discutimos os temas relacionados a esta subcategoria, a 'Epifania do acontecer poético, na validação dos dados, os participantes lembraram-se de que a imagem de $\mathbf{G}$ no painel tinha a mesma conformidade corporal de seu autor: a linha e a curvatura que sua coluna faziam quando ele sentava no canto da sala de convivência do Centro de Atenção Psicossocial, como fazia todos os dias; o desenho do corpo com as pernas unidas e os pés juntos; os braços rentes ao corpo; as mãos inertes depositadas juntas sobre as pernas; a forma de sentar na esquina da sala com o corpo "fechado", "acuado no cantinho" e apenas a cabeça olhando para fora e para cima, para a televisão. Estas eram características claras de $\mathbf{G}$ para o grupo e que, segundo eles, estavam presentes na figura.

Não era a figura que se assemelhava a $\mathbf{G}$ pelos traços de seu rosto ou de seu corpo nela representados por imitação, a imagem não se configurava como um retrato verossímil. Mas era um movimento que se apresentava na figura, um "jeito" de ser de G que ali se presentificava. Parecia que os participantes reconheciam naquela figura uma forma de existência. E isso a tornava mais admirável, não por conta de algum esmero técnico em retratar uma realidade, mas pela capacidade daquela figura, pintada pelas mãos de muitos, capturar uma sensação, uma presença, ainda que fugidia.

Tal percepção exige o trânsito por zonas onde o vazio, o invisível, se torna figura. Convoca um olhar que cria, que transfigura, que transvê, na abertura de um espaço potencial, aquilo que só lá está porque é por nós visto; e uma busca, presente no trabalho artístico, por uma linguagem que configure uma ausência que se faz presença por uma

\footnotetext{
${ }^{1}$ Este artigo é parte da dissertação de mestrado cujo projeto teve aprovação da Comissão de Ética para Análise de Projetos de Pesquisa CAPPesq, do HC- FMUSP, protocolo de pesquisa 1.015/05.

${ }^{2} \mathrm{O}$ termo epifania refere-se a aquilo que surge e/ou se manifesta de forma efêmera.
} 
MECCA, R. C.; CASTRO, E. D. de. Epifania do acontecer. Rev. Ter. Ocup. Univ. São Paulo, v. 20, n. 3, p. 180-187, set./dez. 2009.

experiência de ilusão.

Didi-Huberman (1992 apud TESSLER, 2002), em suas reflexões sobre as modalidades do sensível, propõe que ver é sentir algo que nos escapa. Uma proposição que, segundo a autora que o analisa, é válida para toda espécie de configuração artística. Seja ela referente a pintura ou escultura, objeto representado ou presentificado, o que vemos é sempre mais do que vemos objetivamente. "Há sempre um ponto cego em nosso olhar, que traduz o espaço da perda, o vazio que se instala entre o que vemos e o que nos olha, assinalando o que, no mundo, tem a ver conosco" (TESSLER, 2002, p.72).

Um modo de existência, uma forma do sujeito acontecer no mundo fazem presença nas formas sensoriais criadas. As imagens eram apresentações de formas de ser que aconteciam no momento da criação artística. Este momento que, paradoxalmente, reunia atividade e passividade, concepção e êxtase mobilizado por uma aparição. Aquilo que era criado, muitas vezes, surgia diante de quem o criava como aparição.

D pediu que fosse feita uma foto sua no jardim entre as flores e assegurava que deveria manter a pintura de sua figura apenas com o contorno tracejado na cor marrom, sem preencher o interior com tinta. Alguns participantes se incomodavam, diziam "fica estranho", "parece um fantasma sem corpo", e não entendiam porquê ela não queria pintar dentro do contorno. Mas ela sustentava que era assim que queria sua imagem.

Pode-se lembrar, nesse momento, de sua expectativa no início do grupo de que a realização de atividades pudesse ser uma forma de cuidar da sensação de estagnação que vivia no "hospital". Falou da vida no CAPS como uma seqüência de momentos parados, cortados. O que nos parece remeter a uma sensação de descontinuidade e das situações que vive não terem ligação entre si. "A gente aqui às vezes fica congelado como numa foto". "Eu varro o jardim e as folhas aparecem de baixo da roseira de novo". Falava de uma vida que se repetia e que retornava sempre para o mesmo lugar e de uma ação sua que não produzia efeitos no ambiente, de uma passagem que não deixava marcas, não produzia rastros. Um modo de existência que parecia acontecer na virtualidade, pessoa sem corpo, ações sem forma, passagens errantes, "alma penada" (modo um dos participantes se referiu ao trabalho de D). Posteriormente, D reconheceu-se na fala de outro participante sobre seu trabalho: "parece um anjo".

D dizia que aqueles traços favorecidos pela linha eram os traços de sua raça e que não podia fazer diferente, pois "O guerreiro apareceu na hora da foto", referindo-se à figura que estava pintando. Nesse momento, retomou dados de sua história, perguntando se sabíamos que ela havia sido violentada sexualmente e que sua filha mais nova, era fruto desse estupro. Mais uma outra vez ao falar do guerreiro, retomou situações em que havia salvado os filhos das agressões do pai e referiu ter "sobrevivido" a várias internações. Assim como o guerreiro "aparecia", com ele surgiam situações de violência a que $\mathbf{D}$ fora submetida.

Uma aparição num momento de epifania se configura a partir de um paradoxo entre mistura e distinção de $\mathbf{D}$ com a imagem por ela criada. Como se a imagem do guerreiro naquela hora tomasse a própria imagem de $\mathbf{D}$ e solicitasse dela que os procedimentos para sua configuração fossem executados.

Uma imagem que demonstrava autonomia, aparecia como algo que existia apesar de $\mathbf{D}$, e a ela se apresentava, porém simultaneamente veiculava um modo de estar presente na vida, uma sobrevida de $\mathbf{D}$ às rupturas, violência e falta de suporte que ela enfrentava e à qual necessitava dar corpo e sentido. Uma experiência de encontro intersubjetivo entre $\mathbf{D}$ e o anjo-guerreiro, no qual ambos tomam forma ao mesmo tempo na matéria sensível.

O encontro com as imagens e formas criadas, também, produz a articulação de aspectos do self, que estavam à espera de um outro que os reconhecesse como produção de uma singularidade, com o sensível, de modo que estes podem ganhar corpo e ser apropriados pelo sujeito.

Os participantes, durante a validação, também fizeram uma associação à figura de MA na pintura. Diziam que a figura pintada era "a cara dela". E ao mesmo tempo se espantavam, pois se lembravam que ela no quadro dançava e era conduzida por um outro participante, parecia leve, era colorida; e que no início das atividades do grupo, ela se apresentava de maneira diversa, andava com a ajuda de uma bengala e era uma pessoa extremamente embotada e deprimida.

MA iniciou sua participação na oficina no projeto do painel de pintura a partir das fotografias. No início do grupo, pouco se expressava, sentava-se na ponta da mesa da sala de atividades e dizia não querer fazer nada. Quando ouviu a proposta da produção de cenas para serem fotografadas, referiu que gostaria de tirar uma foto sua dançando. Ela ainda utilizava uma bengala, por conta da fratura no pé após uma tentativa de suicídio e se locomovia com dificuldade. Por isso, muitos se perguntavam se ela de fato dançaria. D dizia "mas como ela vai dançar de bengala e com o pé assim?".

Ela se posicionou no meio do hall de entrada do CAPS e todos os outros participantes do grupo ficaram em volta. Outras pessoas que aguardavam atendimento ficaram observando e quem por lá passava, parava, ou se 
esquivava para não atrapalhar a produção. Alguns dos outros participantes impediam a circulação das demais pessoas como que numa necessidade de suspender o tempo para que a cena ocorresse, ou como quando se pede silêncio para que alguém fale algo importante.

Ela abriu um pouco mais as pernas e estendeu o braço com qual se apoiava na bengala e ficou num sentido diagonal à câmera. De fato, pareceu como uma suspensão de tempo, um estado efêmero e de epifania, em que a atenção de todos se voltava para a cena montada e o momento do "clic" da câmera.

Um momento em que ela própria adquiria plenitude, num cenário com unidade e sentido orgânico e estético. Um estado de coesão momentâneo dela com uma imagem invisível e potencial; e de todos do grupo na configuração de um cenário imaginário que dava abertura ao inusitado e suporte a uma nova configuração de MA.

Experiência estética, na qual MA se apresentava inteira a todos, que em volta acolhiam seu estado de integridade e o apontar de um estilo de si, genuíno e espontâneo quase que por contaminação por uma força de vida. Um momento que unia todos na construção de uma cena de comunhão com a estranheza, imprevisível e fecunda, que se abria a uma potência de vida.

Estado de suspensão em que o fluxo contínuo da vida parecia se congelar num átimo de segundo, sensação instantânea de que algo se eterniza (DERDYK, 2001). A sensação era de uma força poética centrípeta, que integrava a todos numa estrutura cênica e compunha uma narrativa do acontecer de alguém como aparição.

A princípio, para os participantes, ela não parecia estar dançando, ela dançava não-dançando, estado de um gesto em energia potencial, potência do acontecer singular de alguém. Criou-se uma imagem a partir do que não estava lá: dançar, não-dançando, ou seja, a partir da potência do acontecer poético. A fotografia era fragmento que motivava um trabalho imaginativo de composição de uma realidade apenas sugerida, não anterior a ela, mas que se fazia nela, iniciava seu processo de formatividade na imagem do invisível capturado. Uma exacerbação da ambigüidade, loucura e mistério do mundo sensível; imagem que "é" e "não é", "está" e "não está" (FRAYZE-PEREIRA, 2005).

Uma fotografia do invisível, que não tem como objetivo espelhar o mundo, duplicá-lo, ou representar um desejo, mas "inventar mundos possíveis, dar visibilidade ao invisível, desembaraçar nosso olhar tão acostumado, rendido às uniformidades" (PRECIOSA, 2005, p.55). Nessa experiência de dar lugar ao invisível, à potência, exacerbase a sensação do paradoxo da criação de algo que já estava a espera de ser criado, estopim de uma busca por forma e linguagem para configurar uma ausência.

A nosso ver, criar imagens da potência é uma possibilidade não somente do raciocínio do terapeuta em relação ao sujeito que acompanha, como coloca Mattingly (2007), mas também uma possibilidade inerente à experiência estética no processo criativo, que ao mesmo tempo em que aponta para a singularidade enquanto energia potencial, articula-a ao todo e ao coletivo, pois é em si mesma a experiência do apontar do genuíno e também a permissão ao genuíno.

Na situação da fotografia de MA, foi de fundamental importância o reconhecimento do grupo de que aquilo poderia ser algo genuíno dela e também a sustentação dada pelo grupo, que em estado de credulidade própria do brincar e da experiência criativa, abriram espaço, pediram passagem, suspenderam provisoriamente o tempo, esperaram em atenção concentrada o acontecimento.

$\mathrm{O}$ acontecimento poético é um acontecimento inédito, portanto é também ruptura com uma forma de si anterior, porém uma ruptura fundante de uma abertura para a criação de uma nova forma de existência, é uma experiência de liberdade posicionada entre o ser e o não ser.

Porém, para que esta ruptura seja reconhecida como tentativa de encontrar o singular em si, é necessário o reconhecimento de um outro, ou do Outro $^{3}$, como nos aponta Safra (2004).

Segundo o autor, é fundamental a presença do Outro para que o gesto ocorra assentado na esperança de que um acontecer é possível. É preciso a presença do Outro para que o não-ser em potencial seja possibilidade de liberdade, um gesto de afirmação de si.

Uma potência clínica da experiência estética se torna evidente na situação narrada, especialmente quando se trata de alguém cuja alternativa para acontecer ante ao Outro era o suicídio, como único gesto de afirmação de si. "O gesto dirigido ao Outro possibilita o estabelecimento do sentido que, por sua vez, é abertura para a experiência de liberdade e a possibilidade de o indivíduo existir entre os homens"

\footnotetext{
${ }^{3}$ Outro com letra maiúscula por se tratar do sentido ontológico, o nós existencial, representante da humanidade, não apenas de uma outra pessoa em atenção devotada. $\mathrm{O}$ autor se refere a um vértice transcendente implicado nessa concepção que diz respeito ao existir entre outros, na presença humana e, ao mesmo tempo, em meio à natureza, às coisas, aos descendentes, aos ascendentes. Esta noção é encontrada nos estudos do autor sobre a concepção de Sobórnost (unidade, conciliar, comunitário) a partir das leituras dos filósofos russos, Khomiakov e Kireevsky (1998 apud SAFRA, 2004).
} 
(SAFRA, 2004, p.64).

MA começou a trabalhar sobre os recortes das fotocópias coloridas da sua fotografia nas sessões seguintes. Recortou sua imagem dançando e colocou no centro de uma folha. Recortou uma fotografia de todos os participantes sentados um do lado do outro no banco do pátio. Foto que havia sido tirada nos primeiros dias das produções fotográficas para montagem da produção de $\mathbf{M}$, na qual ele imaginava pessoas por entre as árvores ou passando numa praça "como se fosse uma novela". Nesse dia, alguns participantes sentaram no banco e outros passaram cumprimentando os que estavam sentados. D havia comentado que parecia a cena de "um velório".

Quando MA colocou esta imagem no cenário de sua composição por detrás da sua própria imagem fotografada, a cena se transfigurou, e o que antes parecia um velório, sem mobilidade, se tornou o contexto da pista de dança, uns tirando outros para dançar. A imagem dos participantes sentados na pista de dança sugeria a alguns que os personagens eram jurados de um concurso.

Ela recortou também uma outra imagem de $\mathbf{M}$ andando pela quadra de futebol. Recortou mais uma figura de um homem em pé de braços abertos para compor a cena com $\mathbf{M}$ e os outros participantes, que segundo ela, seriam as pessoas da discoteca. Manteve a estrutura redonda que ficava ao fundo de sua imagem, era uma escultura feita no grupo em projetos anteriores, que acabou se transformando no globo da pista de dança.

MA não só transformou sua imagem como montou um cenário de sustentação em que os participantes do grupo, também transformados, ressignificados nas formas plásticas e potencializados pela arquitetura da composição, continuavam a sustentar a apresentação de seu estilo de ser.

Tiramos fotocópia colorida de sua montagem em colagem sobre um papel de transparência e a montagem foi retro-projetada na tela de pano para ser pintada. Com auxilio da coordenação, MA ficou muito atenta aos efeitos produzidos pela projeção para pensar as cores e a textura que iria produzir, aproximava-se e distanciava-se da imagem enquanto pintava, para ver os resultados da textura à distancia. Seu envolvimento no grupo foi ficando mais intenso, assim como seu estado de humor foi se modificando. Ela pouco falava de si, mas estava sempre muito presente no que fazia. Envolvia-se na composição do todo do painel, opinava sobre o lugar que cada imagem iria ocupar e de que forma a projeção deveria ser feita.

A bengala que ela utilizava desapareceu na pintura e o movimento produzido no corpo pela retirada da bengala, dava a sensação de que ela estava "solta, dançando, pronta para dar uma pirueta" (na visão do participante $\mathbf{M}$ ). A figura de M parecia fazer uma torção no corpo para olhá-la e, na validação dos dados, os dois se divertiram dizendo que ele a tirava para dançar.

Com o tempo, ela passou a freqüentar um serviço de reabilitação física para dar continuidade ao tratamento das seqüelas da fratura no pé, o qual havia parado por meses, e passou a vir ao grupo sem a bengala. A figura dela se modificou por completo quando inclusa na pintura, articulada às outras cenas e transformada pelo gesto poético. Ganhou outros sentidos, como a própria MA foi sendo transformada por este processo formativo. A forma corporal de MA mudou, sua postura, seu comportamento, seu humor. Tínhamos a sensação de que ela construía uma nova forma de si, ao mesmo tempo em que formava uma imagem de si na tela. Ambas entravam em composição.

A experiência criativa ocorre nesse encontro, num embaralhamento da distinção sujeito-objeto, no qual não há necessidade de distinguir quem cria e quem é criado. Ao formar gesto e imagem, forma-se a si mesmo.

Preciosa (2005) coloca que o contato com o objeto estético é sempre uma experiência singular, na qual entre duas formas complexas de existência, o sujeito e a obra, acontece uma combinatória possível. O encontro com a obra faz do sujeito outro, pois o desencadeamento de intensas sensações irrompe uma paisagem existencial do sujeito que desaponta revitalizada e refrescada, uma sensação súbita que deserta o sujeito da forma que lhe era familiar, porém desgastada de sentido, ou seja, vão livre por onde podem se firmar outros valores. Há, nesse momento, segundo a autora, um nascimento de si, afirmando uma oportunidade de o sujeito perceber a existência como um interminável ensaio de si mesmo, propulsionado por este novo contorno, menos anestesiado e menos subserviente às padronizações.

No momento da validação, discutimos o estranhamento que a produção por vezes proporcionava: a distância entre o auto-retrato de MA e aquilo que ela aparentava aos outros no início de suas participações na oficina produzia uma sensação "esquisita" que aos poucos foi se dissolvendo pela própria mudança de postura da participante no grupo, pela nova forma que ela construiu para si e pela expressão de seus desejos, projetos e envolvimento na atividade. Os participantes lembraram do dia que ela retornou ao grupo após um tempo fora, durante o qual ela havia feito outra cirurgia no pé fraturado para tirar os pinos. Entrou no grupo com uma roupa "idêntica" a que havia pintado no seu autoretrato, esta situação naquele dia havia impressionado alguns dos participantes.

Um estranhamento se anunciava pela perplexidade com relação ao fato de ser ela e não ser ela ao mesmo tempo, ela era forma que brotava da intimidade com a obra, ela mesma a aparição de sua criação. Processo paradoxal que denotava uma qualidade de presença numa área de jogo em que toda 
a lógica da arte como representação da realidade parecia invertida. Se alguém ali poderia adquirir algum status de representação não era a imagem de MA na tela e sim ela mesma, metalinguagem de si.

Nos encontros seguintes, MA passou a recuperar algumas questões referentes ao seu adoecimento, falou de uma paixão que seria estopim de sua crise. Também relatou ao grupo sobre o salão de baile de propriedade do pai, que na época já não funcionava mais, que havia aprendido a dançar lá e que era muito divertido.

Nos últimos encontros, mobilizada pelo caderno de desenhos que $\mathbf{G}$ havia trazido, resolveu também trazer o caderno de desenhos do irmão falecido, e mostrou para todos do grupo com um ar de orgulho, dizendo que o achava talentoso. Começou a contar do falecimento dos irmãos e que pouco conversava com os pais sobre suas mortes ou qualquer outra coisa. Dizia que era ela a responsável por cuidar das coisas dos irmãos. Na semana seguinte, me solicitou encaminhamento para psicoterapia, pois sentia necessidade de falar de si, já estava de alta do Centro de Atenção Psicossocial e viria somente para a oficina.

Quando discutimos esta categoria, a participante falou do quanto gostava de dançar e que agora tinha voltado a freqüentar espaços de dança com a prima. Contou que voltou a dirigir o carro do pai. Falou de outros desejos que já havia mencionado anteriormente: dos pássaros e do cachorro que teve, os quais seu pai se desfez quando ela adoeceu e foi morar com a prima. "Quero voltar a ter minhas coisas", depois completou "Estas coisas são a minha cara".
Retirada de um estado anestésico, parecia mostrar credulidade e esperança na possibilidade de continuar a ter experiências estéticas, de sempre reencontrar a si mesma nas coisas, nos outros, no mundo.

\section{CONCLUSÃO}

Quando o estilo de ser do sujeito se apresenta e tem lugar na experiência com os outros, ocorre uma propulsão de um contínuo estado de criação de si, de sempre se fazer outro e de ressignificação da existência. A experiência de liberdade do acontecer poético propulsiona "o devir humano em direção a um sentido sempre em transformação ao longo da vida" (SAFRA, 2004, p.62).

Considera-se que a relação intersubjetiva do sujeito com a produção artística é campo favorável à aparição de um estilo de ser na obra, que também aparece como alteridade. Dessa maneira, torna-se possível ao sujeito ver-se como outro de si mesmo e perceber a existência como um contínuo inventar de si. Isto gera uma abertura prospectiva calcada na esperança que o despontar de si como acontecimento em face do Outro possibilita, e na perspectiva de se sentir existindo em continuidade e de sempre se reencontrar no mundo. É um acontecimento intersubjetivo, pois é o apontar e a permissão à potência do acontecer singular de alguém, que pelo reconhecimento do outro vira gesto e afirmação de si. Nesse sentido, é necessário ao terapeuta ver humanidade no ato de fazer-se estilo, vida no ato de fazer-se arte, a pessoa no ato de fazer-se obra (PAREYSON, 1989).

MECCA, R. C.; CASTRO, E. D. de. Epiphany of the poetic occurrence: aspects of the aesthetic experience in between subject-work of art relation in occupational therapy. Rev. Ter. Ocup. Univ. São Paulo, v. 20, n. 3, p. 180-187, set./dez. 2009.

\begin{abstract}
S: The aesthetic experience is approached as a phenomenon inherent to the subjectwork of art relation in the context of the practice in occupational therapy in mental health. Those are situations in the practical experience related to the possibility of subjects finding aspects of their own style of being in an I-other relation with the product of their artistic creation. The objective is to understand which is the contribution that the aesthetic experience brings to the subjects' poetic occurrence, the emergence of their creative gestures and to the beginning of the construction of their way of shaping. A process which, in the very sensible matter being shaped, helps recomposing the fragments of their personal history, builds up sense and shape for the existence, for the daily experiences, and allows the recognition of the surrounding environment in a singular way of existing in the world. The article is part of the results of our Masters' dissertation, which includes a field research to follow up the process of conducting artistic activities by a group of users of a mental-health service unit with further qualitative analysis of the data. The active contribution of the participants of said group in the collection and analysis of the data composes the procedures carried out according to a full and systemic research-action. The results point out that the meeting with the work allows the appearance of new softened ways of being, fertilized by a singularizing process and a prospective opening to processes of a continuous invention of oneself.
\end{abstract}

KEY WORDS: Occupacional Therapy. Mental health. Art. 
MECCA, R. C.; CASTRO, E. D. de. Epifania do acontecer. Rev. Ter. Ocup. Univ. São Paulo, v. 20, n. 3, p. 180-187, set./dez. 2009.

\section{REFERÊNCIAS}

DERDYK, E. Ponto de chegada, ponto de partida. In: SOUSA, E.; TESSLER, E., et. al. A invenção da vida: arte e psicanálise. Porto Alegre: Artes e Ofícios, 2001. p. 14-21.

FRAYZE- PEREIRA, J. A. Arte, dor-inquietudes entre psicanálise e estética. Cotia, SP: Ateliê Editorial, 2005.

MATTINGLY, C. A natureza narrativa do raciocínio clínico. Rev Centro Estudos Ter. Ocup. São Paulo, v. 10, n. 10, p.4-18, 2007.

MECCA, R. C. Experiência estética na terapia ocupacional em saúde mental: gestos na matéria sensivel e alojamento no mundo humano. 2008. 263 f. Dissertação (Mestrado) - Faculdade de Medicina da Universidade de São Paulo. São Paulo, 2008.

MEYER, J. Usando métodos qualitativos na pesquisa-ação relacionada à saúde. In: POPE, C.; MAYS, N. (orgs.) Pesquisa qualitativa na atenção à saúde. 2a ed. Porto Alegre: Artmed, 2005. p. 71-86.

MORIN, A. Pesquisa-ação integral e sistêmica: uma antropopedagogia renovada. Rio de Janeiro: DP\&A, 2004.

PAREYSON, L. Os problemas da estética. São Paulo: Martins Fontes, 1989.

PRECIOSA, R. S. Produção estética: notas sobre roupas, sujeitos e modos de vida. São Paulo: Ed. Anhembi Morumbi, 2005.

SAFRA, G. A face estética do self-teoria e clínica. São Paulo: Unimarco, 1999.

SAFRA, G. A pó-ética na clínica contemporânea. Aparecida, SP: Idéias \& Letras, 2004.

SOUSA, E. L. A. Quando atos se tornam formas. In: BARTUCCI, G. (org.) Psicanálise, arte e estética da subjetivação. Rio de Janeiro: Imago, 2002. p. 143-152.

TESSLER, E. Tudo é figura ou faz figura. In: BARTUCCI, G. (org.) Psicanálise, arte e estética da subjetivação. Rio de Janeiro: Imago, 2002. p. 69-82. 